OPEN ACCESS

Edited by:

Wanjun Chen,

National Institutes of Health (NIH),

United States

Reviewed by:

Christopher E. Rudd,

Université de Montréal, Canada

Xiao He,

The University of Utah, United States

*Correspondence:

Jongdae Lee

j142lee@gmail.com

j142lee@health.ucsd.edu

Jose M. González-Navajas

gonzalez_josnav@gva.es

Specialty section

This article was submitted to

T Cell Biology,

a section of the journal

Frontiers in Immunology

Received: 03 November 2020

Accepted: 02 February 2021

Published: 26 February 2021

Citation:

González-Navajas JM, Fan DD,

Yang S, Yang FM, Lozano-Ruiz B, Shen $L$ and Lee $J$ (2021) The Impact of Tregs on the Anticancer Immunity and the Efficacy of Immune

Checkpoint Inhibitor Therapies.

Front. Immunol. 12:625783.

doi: 10.3389/fimmu.2021.625783

\section{The Impact of Tregs on the} Anticancer Immunity and the Efficacy of Immune Checkpoint Inhibitor Therapies

\author{
Jose M. González-Navajas ${ }^{1,2,3,4 *}$, Dengxia Denise Fan ${ }^{5}$, Shuang Yang ${ }^{5}$, \\ Fengyuan Mandy Yang ${ }^{5}$, Beatriz Lozano-Ruiz ${ }^{1,2}$, Liya Shen ${ }^{5}$ and Jongdae Lee ${ }^{5 *}$ \\ ${ }^{1}$ Alicante Institute for Health and Biomedical Research (ISABIAL), Hospital General Universitario de Alicante, Alicante, Spain, \\ ${ }^{2}$ Networked Biomedical Research Center for Hepatic and Digestive Diseases (CIBERehd), Institute of Health Carlos III, \\ Madrid, Spain, ${ }^{3}$ Department of Pharmacology, Pediatrics and Organic Chemistry, University Miguel Hernández, Elche, Spain, \\ ${ }^{4}$ Institute of Research, Development and Innovation in Healthcare Biotechnology in Elche (IDiBE), University Miguel \\ Hernández, Elche, Spain, ${ }^{5}$ State Key Laboratory of Respiratory Disease, School of Basic Medical Sciences, Guangzhou \\ Medical University, Guangzhou, China
}

Although cancers arise from genetic mutations enabling cells to proliferate uncontrollably, they cannot thrive without failure of the anticancer immunity due in a large part to the tumor environment's influence on effector and regulatory $T$ cells. The field of immune checkpoint inhibitor $(\mathrm{ICl})$ therapy for cancer was born out of the fact that tumor environments paralyze the immune cells that are supposed to clear them by activating the immune checkpoint molecules such as PD-1. While various subsets of effector T cells work collaboratively to eliminate cancers, Tregs enriched in the tumor environment can suppress not only the native anticancer immunity but also diminish the efficacy of $\mathrm{ICl}$ therapies. Because of their essential role in suppressing autoimmunity, various attempts to specifically deplete tumor-associated Tregs are currently underway to boost the efficacy of $\mathrm{ICl}$ therapies without causing systemic autoimmune responses. A better understanding the roles of Tregs in the anti-cancer immunity and $\mathrm{ICl}$ therapies should provide more specific targets to deplete intratumoral Tregs. Here, we review the current understanding on how Tregs inhibit the anti-cancer immunity and ICI therapies as well as the advances in the targeted depletion of intratumoral Tregs.

Keywords: immune checkpoint inhibitor (ICI), Tregs, Treg-depletion, Foxp3, PD-1, CTLA-4

\section{INTRODUCTION}

ICI therapies targeting programmed death 1 (PD-1), programmed death ligand 1 (PD-L1), or cytotoxic $\mathrm{T}$ lymphocyte-associated antigen 4 (CTLA-4) have effectively treated various types of cancer. PD-1 is induced in activated T cells while its ligand PD-L1 is expressed in many cell types including antigen-presenting cells (APCs) and tumor cells. PD-1/PDL1 interaction inhibits $\mathrm{T}$ cell survival and proliferation (1). CTLA-4 is also induced on activated $\mathrm{T}$ cells and has a much stronger affinity than CD28 to B7 molecules (CD80 and CD86) in APCs, thus competing with APCs for B7 and inhibiting full activation of $\mathrm{T}$ cells (2). Unfortunately, only a fraction of patients responds to these therapies, leaving the vast majority without benefit (3). While ICI therapies understandably have 
focused on reinvigorating cytotoxic responses by $\mathrm{CD} 8^{+}$or $\mathrm{NK}$ cells, growing evidence indicates that $\mathrm{CD} 4^{+} \mathrm{T}$ cell subsets have differential influences on the efficacy of ICIs (The multifaceted role of Th1, Th9 and Th17 cells in immune checkpoint inhibition therapy). One of the reasons for the poor response to ICIs in many patients has been attributed to intratumoral regulatory $\mathrm{T}$ cells (Tregs). As Tregs are essential in maintaining immune homeostasis and preventing autoimmunity, deficiencies in Treg development or function cause uncontrolled immune responses and autoimmune diseases (4). However, intratumoral Tregs may promote tumor progression by suppressing the natural anticancer immune responses. The percentage of Tregs among $\mathrm{CD}^{+}{ }^{+}$cells is significantly higher in tumors compared to its share in the immune organs (5-8). The increased percentage of Tregs in many cancers is often associated with poor prognosis (9). Therefore, the impact of Tregs should be considered for successful ICI therapies. In this review, we discuss the role of Tregs in the anticancer immunity and ICI therapies as well as the strategies being developed to specifically deplete intratumoral Tregs.

\section{BRIEF OVERVIEW OF Treg DEVELOPMENT AND DIVERSITY}

Tregs, originally identified by Sakaguchi et al. as $\mathrm{CD} 4^{+} \mathrm{CD} 25^{+}$ $\mathrm{T}$ cells essential for self-tolerance (10), are divided in several subsets in mice (Table 1). Natural regulatory T cells (nTregs) are induced by a broad spectrum of autoantigens in the thymus, thus also called tTregs. On the other hand, peripherally derived Tregs (pTregs) or induced Tregs (iTregs) are differentiated from naive $\mathrm{CD} 4^{+} \mathrm{T}$ cells in the periphery or in vitro, respectively, by various factors including transforming growth factor- $\beta$ (TGF- $\beta$ ), dendritic cells (DCs) expressing indole amine 2,3-dioxygenase (IDO), or retinoic acid (11). While the master transcription factor Foxp3 (forkhead box P3) expression in both subsets is essential for their suppressive function, there are important differences between them. For instance, tTregs express a high level of Helios and Neuropilin-1 (NRP1) whereas pTregs express very little of them $(12,13)$. There are two other $\mathrm{CD} 4{ }^{+}$Treg subsets that do not express Foxp3, IL-10-producing T regulatory type 1 ( $\operatorname{Tr} 1)$ cells (14) and TGF- $\beta$-producing T helper type 3 (Th3) cells (15). In addition, there are $\mathrm{CD} 8^{+}$Tregs that express Foxp3, that are the

TABLE 1 | Treg subsets.

\begin{tabular}{|c|c|c|}
\hline Species & Names & Markers \\
\hline \multirow[t]{4}{*}{ Mouse } & nTreg or tTreg & $\mathrm{CD}^{+}{ }^{+} \mathrm{CD} 25^{+} \mathrm{Foxp}^{+}$Helios $^{\text {high }} \mathrm{NRP} 1^{+}$ \\
\hline & pTreg & $\mathrm{CD}^{+}{ }^{+} \mathrm{CD}_{25}{ }^{+} \mathrm{Foxp}^{+}$ \\
\hline & iTreg (in vitro generated) & $\mathrm{CD}^{+}{ }^{+} \mathrm{CD}_{25}{ }^{+} \mathrm{Foxp}^{+}$ \\
\hline & $\operatorname{Tr} 1$ & $\mathrm{CD}^{+}{ }^{+} \mathrm{Foxp}^{-} \mathrm{IL}_{-10^{+}}$ \\
\hline \multirow[t]{2}{*}{ Human } & nTreg & $\mathrm{CD}^{+}{ }^{+} \mathrm{CD} 45 \mathrm{RA}^{+}{ }^{+}$Foxp3 ${ }^{\text {low }} \mathrm{CD} 127^{\text {low }}$ \\
\hline & eTreg & CD4+CD45RA-Foxp3 ${ }^{\text {high }}$ \\
\hline
\end{tabular}

Foxp3, Forkhead box P3; Treg, regulatory T cell; nTreg (mouse), natural Treg; tTreg, thymus-derived Treg; pTreg, peripheral Treg; iTreg, induced Treg; Tr1, T regulatory Type 1; nTreg (human), naive Treg; eTreg, effector Treg. first reported suppressor T cells, and regulatory B cells (Bregs) that suppress the proliferation of lymphocytes, including effector $\mathrm{T}$ cells mainly via secretion of IL-10. Herein, we will mostly focus on $\mathrm{CD}^{+}{ }^{+} \mathrm{Foxp}^{+}$Tregs. Treg heterogeneity was reviewed previously $(16,17)$. As non-Tregs cells in humans also express Foxp3 when acutely activated, Tregs are classified based on the expression of other markers such as CD45RA and CD127 in addition to Foxp3. Weakly suppressive naive Treg cells (nTreg: $\mathrm{CD} 4{ }^{+} \mathrm{CD} 45 \mathrm{RA}^{+}$Foxp $3{ }^{\text {low }} \mathrm{CD} 127^{\text {low }}$ cells) can differentiate into effector Tregs (eTreg: CD4 ${ }^{+}$CD $45 \mathrm{RA}^{-}$Foxp $3^{\text {high }}$ cells), which are activated and highly suppressive $(18,19)$. In conclusion, Tregs come in a variety of different forms depending on species and locality (20), and thus are expected to express different sets of surface markers and functions, especially in different tumor microenvironments.

\section{SUPPRESSIVE MECHANISMS OF Tregs}

Both nTregs and pTregs suppress the functions of $\mathrm{T}$ cells as well as other immune cells including B cells, NK cells, dendritic cells (DCs), and macrophages via humoral (IL-10, TGF- $\beta$, IL-35, granzyme B, adenosine, cAMP) and cell-cell contact mechanisms (CTLA4, GITR, LAG3). The detailed mechanisms were reviewed elsewhere (4). Although the local environment influences which of these mechanisms Tregs use to suppress immune responses, Foxp3-regulated genes are most likely essential for the Treg functions. Foxp3 controls the expression of IL-2, CD25 (IL-2 receptor $\alpha$-chain), CD122 (IL- 2 receptor $\beta$-chain), and CTLA-4, and deficiency in any of them results in autoimmune diseases observed in Foxp3 deficiency (21). It is noteworthy that the canonical Th2 transcription factor GATA binding protein 3 (GATA-3) is important for maintaining Foxp3 expression and Treg suppressive function $(22,23)$.

Tregs rely on IL-2 produced by effector T cells for survival and proliferation since Foxp3 suppresses IL-2 expression (24). However, Tregs express a higher level of the high-affinity IL-2 receptor complex comprised of IL-2R $\alpha$ (CD25), IL2R $\beta$ (CD122), and IL-2R $\gamma$ (CD132) (10), which, acting as an IL-2 sink, can starve other $\mathrm{T}$ cells of IL-2. Therefore, exogenous IL-2 can rescue effector $\mathrm{T}$ cells from IL-2 depravation mediated by Tregs in vitro (25). Theoretically, IL-2 supplementation during ICI therapies may also relieve effector T cells of IL-2 depravation where Tregs are enriched. However, systemic administration of IL-2 at a high dose is risky as it can cause severe inflammation. A low dose IL-2 or a modified IL-2 that can only bind to the high-affinity IL-2 receptor can be considered to minimize the systemic effect (26-28), which can be useful for activating Tregs to suppress hyper-inflammation.

CTLA-4 is highly expressed in Tregs but also in activated effector T cells. CTLA-4 has a much higher affinity than CD28 for their common ligands CD80 and CD86, thus preventing CD28 in effectors $\mathrm{T}$ cells from being activated by CD80/CD86 in APCs (2). It also modulates T cells motility and interactions with APCs (29). However, CTLA-4 regulates $\mathrm{CD}^{+}$and $\mathrm{CD}^{+}$cells differentially since Chambers et al. 
showed that lymphoproliferation in CTLA-4 $4^{-/-}$mice was due to costimulation-dependent activation of $\mathrm{CD}^{+}{ }^{+}$cells (30). Ipilimumab (anti-CTLA-4 mAb) appears to be working in part by depleting Tregs via antibody-dependent cellular cytotoxicity (ADCC) in animal studies (31-33). Sharma et al. reported that anti-CTLA-4 Abs (Ipilimumab and Tremelimumab) did not deplete Foxp $3^{+}$cells within the tumor microenvironment, but suggested modifying the $\mathrm{Fc}$ region of the antibodies to enhance Fc-mediated depletion of intratumoral Tregs (34). Indeed, an anti-CTLA-4 mAb engineered for high ADCC depleted Treg cells more effectively (35). Although the clinical benefit of Ipilimumab treatment highly correlated with the decreased number of intratumoral Tregs (36), further studies are needed to determine the precise role of anti-CTLA- 4 therapy has on intratumoral Tregs.

In conclusion, although Tregs use a host of different mechanisms to suppress T and other cell types, IL-2 depletion and up-regulation of CTLA-4 mediated by Foxp3 appear to be the most relevant in suppressing anticancer immunity.

\section{THE ROLE OF Tregs ON CANCER DEVELOPMENT}

It is quite clear in mice that Tregs suppress tumor-specific effector $\mathrm{T}$ cells since mice depleted of Tregs by anti-CD25 antibody or T cell-deficient mice reconstituted only with effector $\mathrm{T}$ cells effectively eliminate a variety of syngeneic tumors (37, 38). Several lines of evidence suggest that this is also true in humans. Tregs are over-represented in a number of tumors compared to immune organs or blood (5-8). The reasons for the increased intratumoral Tregs numbers over effector $\mathrm{T}$ cells include recruitment via different chemokines secreted by various tumor cells and other cells in the tumor microenvironment $(7,39,40)$, local expansion of Tregs activated by self-antigens presented by dying tumor cells $(41,42)$, the ability of Treg cells to adapt their metabolism to the tumor microenvironment $(43,44)$, and differentiation of naïv $\mathrm{T}$ cells to pTregs (45). Intratumoral Tregs are more powerful suppressors relative to Treg derived from the patient's autologous blood (46-48). The number of intratumoral Tregs is negatively correlated to poor prognosis (8). However, in cancers that share a common feature of prominent chronic inflammation, such as colon, breast, bladder, or head and neck cancers, accumulation of Tregs in tumors is associated with favorable prognosis by potentially suppressing tumor-promoting inflammation (7). The discrepancy may be attributed at least in part to the fact that non-Tregs also express Foxp3 when activated (9), and thus highly suppressive effector Tregs may have been over-estimated in some studies (8). Overall, Tregs suppress immune surveillance against tumor development and progression.

\section{EFFECTS OF ANTICANCER IMMUNOTHERAPY ON Tregs}

The current immunotherapies target either PD-1/PDL-1 and/or CTLA-4 to energize effectors T cells. However, Tregs in the tumor microenvironment also express both PD-1 and CTLA-4 at a high level compared to effector T cells. PD-1 appears to inhibit the suppressive function of intratumoral Tregs. Indeed, PD1 inhibition significantly promoted the proliferation of highly suppressive PD- $1^{+}$effector Treg cells in patients who developed hyperprogressive disease after the anti-PD-1 mAb Nivolumab treatment, resulting in inhibition of antitumor immunity (49). Initially it was thought that CTLA-4 blockade in Tregs would reactivate effector $\mathrm{T}$ cells to attack tumors by allowing CD28 in $\mathrm{T}$ cells to bind to B7 molecules in APCs. However, anti-CTLA4 antibody (Ipilimumab) preferentially depleted intratumoral Tregs by ADCC and antibody-dependent cellular phagocytosis (ADCP) (35). These findings suggested that a combination of PD-1 and CTLA-4 blockers is likely to synergize to activate intratumoral effector $\mathrm{T}$ cells by relieving effector $\mathrm{T}$ cells from PD-1/PDL-1-mediated anergy and depleting intratumoral Treg, respectively. Indeed, the combination of Ipilimumab (antiCTLA-4) and Nivolumab (anti-PD-1) significantly enhanced efficacy in metastatic melanoma patients and probably is more effective in other cancers than monotherapies (50, 51). The combination therapy was approved for treatment of other cancers including metastatic melanoma, advanced renal cell carcinoma and metastatic colorectal cancer with MMR/MSI-H aberrations.

\section{THERAPEUTIC TARGETS TO SPECIFICALLY DEPLETE INTRATUMORAL Tregs}

Several lines of evidence suggest that intratumoral Tregs are a major obstacle in ICI therapies. First, as mentioned above, the percentage of intratumoral Tregs among $\mathrm{CD} 4^{+} \mathrm{T}$ cells is higher than that of Tregs in peripheral blood; second, intratumoral Tregs show a highly activated suppressive phenotype (52); third, depletion of Tregs enhances anticancer immunity in mice and humans. Therefore, intensive efforts are ongoing to find a way to deplete intratumoral Tregs to enhance ICI therapies without activating autoimmune response. The targets should be either exclusively expressed or highly enriched in intratumoral Tregs, preferably on the surface.

CD25 (IL-2R $\alpha)$ is constitutively expressed in Tregs and induced in activated effector $\mathrm{T}$ cells. Systemically targeting CD25 can cause severe inflammation, and thus alternative approaches to target CD25 exclusively in intratumoral Tregs are being investigated. For example, Vargas et al. found that upregulation of the inhibitory Fc gamma receptor $(\mathrm{Fc} \gamma \mathrm{R}) \mathrm{IIb}$ at the tumor site prevented intratumoral Tregs depletion by antiCD25 antibodies. An anti-CD25 antibody with a higher affinity to activating Fc $\gamma$ Rs effectively depleted intratumoral Tregs cells and induced complete tumor rejection in combination with antiPD-1 antibody (53). Sato et al. developed to a photoactivable antiCD25 antibody that can be targeted by near-infrared radiation to deplete intratumoral Tregs (54). Recently, Solomon et al. reported efficient depletion of Tregs with an anti-CD25 antibody (RG6292) without inhibiting IL-2 signaling in effector T cells in both nonhuman primates and humanized mouse models, 
synergistically enhancing an ICI therapy but without overt immune responses (55).

Intratumoral Tregs express several surface molecules at a higher level than Tregs in normal tissues or blood such as PD1, PD-L1, PD-L2, TIGIT, GITR, OX-40, TIM-3, and 4-1BB (56), suggesting they are activated and highly suppressive. Among them, activation of ICOS, 4-1BB, and GITR was shown to inhibit Treg suppressive function but stimulate effector T cells $(57,58)$, leading to several clinical trials. Agonistic anti-OX40 mAb (59) is being tried as a monotherapy or a combination therapy with ICI on solid tumors (NCT02221960). GITR agonists are also being tested on solid tumors alone or in combinations with ICIs (NCT02583165 and NCT02628574) (60). The agonistic antiICOS mAb JTX-2011 is currently being evaluated in a clinical trial (NCT02904226) alone or in combination with a fixed dose of Nivolumab in people with advanced solid tumors. It will be interesting to see if these therapies indeed work on tumors by inhibiting Tregs while activating effector T cells.

The fact that Tregs are enriched in the tumor tissues compared to other organs or blood led to search for chemokines and chemokine receptors essential to recruiting Tregs to tumors. Different tumors harbor Tregs expressing different chemokine receptors (7), therefore, the chemokine receptor expression pattern in intratumoral Tregs can be exploited to enhance ICI therapies. CCR4-expressing Tregs were shown to be attracted to CCL22 released by macrophages within ovarian cancer, which was associated with a decreased survival rate (39), and the antiCCR4 mAb Mogamulizumab effectively depleted effector Tregs in humans to elicit anticancer response (61), which is now being trialed alone or in combination with ICIs in solid tumors (62). CCL28 induced by hypoxia in ovarian cancer recruited CCR10 ${ }^{+}$ Tregs, promoting tumor tolerance and angiogenesis (40). In a murine model of pancreatic cancer, a blockade of the CCR5CCL5 axis inhibited recruitment of Tregs and inhibited tumor growth (63). Specificity of Treg chemotaxis to tumors needs further investigation for clinical application.

Another approach to disable intratumoral Tregs is to selectively convert them into effector $\mathrm{T}$ cells, although this approach is still in an early stage of development. Several molecules are essential for maintenance of Treg functions besides Foxp3, including OX-40, GITR, the histone methyltransferase EZH2, and Helios. Tumor-infiltrating Tregs are dependent on EZH2, an epigenetic switch, to maintain Treg stability and function $(64,65)$. A small molecule inhibitor of EZH2 drove intratumoral Tregs to acquire pro-inflammatory functions, leading to remodeling the tumor microenvironment and enhancing the anticancer immunity without provoking systemic autoimmunity (66). Helios is essential for the maintenance of Treg stability under inflammatory conditions such as autoimmune diseases and cancers. CD4 Treg-specific deletion of Helios enhanced antitumor immunity by induction of an unstable phenotype and conversion of intratumoral Tregs into $\mathrm{T}$ effector cells within the tumor microenvironment (67).

Recently, Ho et al. found that CD36 was selectively upregulated in intratumoral Treg cells in lung cancers and melanomas and that CD36 deletion in Tregs suppressed tumor growth without causing systemic autoimmune response (68).
TABLE 2 | Approaches to deplete or disable intratumoral Tregs.

\begin{tabular}{|c|c|c|}
\hline Modes & Target & Drugs \\
\hline \multirow{4}{*}{$\begin{array}{l}\text { Checkpoint } \\
\text { molecules }\end{array}$} & OX40 & OX40 Agonist Ab MEDI0562 (59) \\
\hline & ICOS & $\begin{array}{l}\text { ICOS Agonist Ab JTX-2011 } \\
(73,74)\end{array}$ \\
\hline & GITR & $\begin{array}{l}\text { GITR Agonist Ab BMS-986156 } \\
\text { (60) }\end{array}$ \\
\hline & CTLA-4 & $\begin{array}{l}\text { Ipilimumab, ADCC-optimized } \\
\text { anti-CTLA-4 Ab (35) }\end{array}$ \\
\hline \multirow{3}{*}{$\begin{array}{l}\text { Blocking Treg } \\
\text { chemotaxis to tumors }\end{array}$} & CCR4 & Mogamulizmab (61) \\
\hline & CCR5 & Anti-CCR5 Ab (63) \\
\hline & CCR10 & $\begin{array}{l}\text { Anti-CCR10 Ab immunotoxin } \\
(40)\end{array}$ \\
\hline \multirow[t]{2}{*}{$\begin{array}{l}\text { Conversion of Tregs } \\
\text { to effector T cells }\end{array}$} & $\mathrm{EZH} 2$ & $\begin{array}{l}\text { Several inhibitors including } \\
\text { GSK343 }(66,75)\end{array}$ \\
\hline & Helios & $\begin{array}{l}\text { An inhibitor of Helios to be } \\
\text { developed }\end{array}$ \\
\hline \multirow{2}{*}{$\begin{array}{l}\text { Others surface } \\
\text { molecules }\end{array}$} & CD36 & CD36 deletion Ab (68) \\
\hline & CD25 & $\begin{array}{l}\text { Fc-optimized depletion CD25 Ab } \\
\text { (53), photoactivable CD25 Ab (54) } \\
\text { Treg-depleting CD25 Ab } \\
\text { (RG6292) (55) }\end{array}$ \\
\hline
\end{tabular}

$A b$, Antibody; ADCC, antibody-dependent cellular cytotoxicity; CCR, C-C motif chemokine receptor; EZH2, Enhancer of zeste 2 polycomb repressive complex 2; CTLA4, Cytotoxic Tlymphocyte antigen 4; GITR, Glucocorticoid-induced TNFR-related protein; ICOS, Inducible T cell co-stimulator; OX-40, TNF receptor superfamily member 4.

In this study, as CD36 in Tregs was important to suppress the anticancer immunity, a monoclonal antibody that blocked CD36 from bonding to fatty acids and to oxidized LDLs induced apoptosis of Treg cells while promoting the accumulation of $\mathrm{CD}^{+} \mathrm{T}$ cells in the tumor. Whether this phenomenon is unique to certain cancers remains to be seen.

TGF- $\beta$ is essential for development of Tregs as well as Th17 cells and was originally thought to be secreted primarily by cancer cells and/or Tregs in the tumor microenvironment. However, the major source of TGF- $\beta$ in tumors was reported to be CD4 ${ }^{+}$Th cells (69-71). Recently Li et al. reported that TGF- $\beta$ suppresses Th2 cell-mediated anticancer immunity in an autocrine fashion and that blocking TGF- $\beta$ signaling in $\mathrm{CD} 4^{+} \mathrm{T}$ cells inhibited cancer progression (72). In this study, the effects of TGF$\beta$ blockade on Tregs were not analyzed. Identifying exclusive markers of intratumoral Th2 cells to deplete them or systemic TGF- $\beta$ blockade can be considered in combination with ICIs.

In conclusion, a growing number of options to deplete or disable intratumoral Tregs are being developed and tested. Most of these approaches require a precise characterization of Treg phenotypes, which is not always possible. These approaches are summarized in Table 2.

\section{CONCLUSION}

There is a growing consensus that intratumoral Tregs promote tumorigenesis and progression and inhibit ICI therapies by suppressing anticancer immunity. The critical question is then 
how to disable or deplete Tregs inside tumors specifically to avoid systemic inflammation. Fortunately, there has been a significant progress in characterizing the phenotypes of intratumoral Tregs that are distinct from those of Tregs in the periphery or normal tissues. With continuing technical advances to take advantage of these findings to target intratumoral Tregs, the future is promising. However, some questions remain to be answered even if some of these approaches are eventually approved for clinical uses. Should Treg depletion be applied to all ICI therapies or selectively? What should be the selection criteria for the latter? Furthermore, all the cutting-edge medicines including ICI therapies are prohibitively expensive for the vast majority of patients, thus leaving most people in the developing countries out of reach. Therefore, more research should be done to bring down the cost of these medicines.

\section{REFERENCES}

1. Patsoukis N, Wang Q, Strauss L, Boussiotis VA. Revisiting the PD-1 pathway. Sci Adv. (2020) 6:eabd2712. doi: 10.1126/sciadv.abd2712

2. Alegre ML, Frauwirth KA, Thompson CB. T-cell regulation by CD28 and CTLA-4. Nat Rev Immunol. (2001) 1:220-8. doi: 10.1038/35105024

3. Topalian SL, Sznol M, McDermott DF, Kluger HM, Carvajal RD, Sharfman $\mathrm{WH}$, et al. Survival, durable tumor remission, and long-term safety in patients with advanced melanoma receiving nivolumab. J Clin Oncol. (2014) 32:102030. doi: 10.1200/JCO.2013.53.0105

4. Vignali DA, Collison LW, Workman CJ. How regulatory T cells work. Nat Rev Immunol. (2008) 8:523-32. doi: 10.1038/nri2343

5. Sakaguchi S, Miyara M, Costantino CM, Hafler DA. FOXP3+ regulatory T cells in the human immune system. Nat Rev Immunol. (2010) 10:490-500. doi: 10.1038/nri2785

6. Miyara M, Yoshioka Y, Kitoh A, Shima T, Wing K, Niwa A, et al. Functional delineation and differentiation dynamics of human CD4+ T cells expressing the FoxP3 transcription factor. Immunity. (2009) 30:899-911. doi: 10.1016/j.immuni.2009.03.019

7. Saleh R, Elkord E. FoxP3(+) T regulatory cells in cancer: prognostic biomarkers and therapeutic targets. Cancer Lett. (2020) 490:174-85. doi: 10.1016/j.canlet.2020.07.022

8. Saito T, Nishikawa H, Wada H, Nagano Y, Sugiyama D, Atarashi K, et al. Two FOXP3(+)CD4(+) T cell subpopulations distinctly control the prognosis of colorectal cancers. Nat Med. (2016) 22:679-84. doi: 10.1038/nm.4086

9. Tanaka A, Sakaguchi S. Targeting Treg cells in cancer immunotherapy. Eur J Immunol. (2019) 49:1140-6. doi: 10.1002/eji.201847659

10. Sakaguchi S, Sakaguchi N, Asano M, Itoh M, Toda M. Immunologic selftolerance maintained by activated $\mathrm{T}$ cells expressing IL-2 receptor alphachains (CD25). Breakdown of a single mechanism of self-tolerance causes various autoimmune diseases. J Immunol. (1995) 155:1151-64.

11. Savage PA, Klawon DEJ, Miller CH. Regulatory T cell development. Annu Rev Immunol. (2020) 38:421-53. doi: 10.1146/annurev-immunol-100219-020937

12. Sarris M, Andersen KG, Randow F, Mayr L, Betz AG. Neuropilin1 expression on regulatory $\mathrm{T}$ cells enhances their interactions with dendritic cells during antigen recognition. Immunity. (2008) 28:402-13. doi: 10.1016/j.immuni.2008.01.012

13. Getnet D, Grosso JF, Goldberg MV, Harris TJ, Yen HR, Bruno TC, et al. A role for the transcription factor Helios in human CD4(+)CD25(+) regulatory $\mathrm{T}$ cells. Mol Immunol. (2010) 47:1595-600. doi: 10.1016/j.molimm.2010.02.001

14. Zeng $\mathrm{H}$, Zhang $\mathrm{R}$, Jin $\mathrm{B}$, Chen L. Type 1 regulatory $\mathrm{T}$ cells: a new mechanism of peripheral immune tolerance. Cell Mol Immunol. (2015) 12:566-71. doi: $10.1038 / \mathrm{cmi} .2015 .44$

15. Carrier Y, Yuan J, Kuchroo VK, Weiner HL. Th3 cells in peripheral tolerance. I. Induction of Foxp3-positive regulatory $\mathrm{T}$ cells by Th3 cells derived from TGF-beta T cell-transgenic mice. J Immunol. (2007) 178:179-85. doi: 10.4049/jimmunol.178.1.179

\section{AUTHOR CONTRIBUTIONS}

$\mathrm{JL}$ and JG-N conceived the manuscript idea and revised the manuscript content. BL-R, FY, LS, and DF edited the text and created the manuscript tables. All authors contributed significantly to the drafting and editing of this manuscript and read and agreed to the final version of the manuscript.

\section{FUNDING}

This work was supported by grant PI19/01554 from the Instituto Nacional de Salud Carlos III (co-financed with FEDER funds), Madrid, Spain; grant CDEI-03/20-A from Generalitat Valenciana, Valencia, Spain to JG-N; Guangzhou Medical University Startup Fund to JL.

16. Shevyrev D, Tereshchenko V. Treg heterogeneity, function, and homeostasis. Front Immunol. (2019) 10:3100. doi: 10.3389/fimmu.2019.03100

17. Workman CJ, Szymczak-Workman AL, Collison LW, Pillai MR, Vignali DA. The development and function of regulatory T cells. Cell Mol Life Sci. (2009) 66:2603-22. doi: 10.1007/s00018-009-0026-2

18. Shitara K, Nishikawa $H$. Regulatory $T$ cells: a potential target in cancer immunotherapy. Ann N Y Acad Sci. (2018) 1417:104-15. doi: $10.1111 /$ nyas. 13625

19. Liu W, Putnam AL, Xu-Yu Z, Szot GL, Lee MR, Zhu S, et al. CD127 expression inversely correlates with FoxP3 and suppressive function of human CD4+ T reg cells. J Exp Med. (2006) 203:1701-11. doi: 10.1084/jem.200 60772

20. Miragaia RJ, Gomes T, Chomka A, Jardine L, Riedel A, Hegazy $\mathrm{AN}$, et al. Single-Cell transcriptomics of regulatory $\mathrm{T}$ cells reveals trajectories of tissue adaptation. Immunity. (2019) 50:493-504.e7. doi: 10.1016/j.immuni.2019.01.001

21. Bennett CL, Christie J, Ramsdell F, Brunkow ME, Ferguson PJ, Whitesell $\mathrm{L}$, et al. The immune dysregulation, polyendocrinopathy, enteropathy, Xlinked syndrome (IPEX) is caused by mutations of FOXP3. Nat Genet. (2001) 27:20-1. doi: 10.1038/83713

22. Wang Y, Su MA, Wan YY. An essential role of the transcription factor GATA-3 for the function of regulatory T cells. Immunity. (2011) 35:337-48. doi: 10.1016/j.immuni.2011.08.012

23. Wohlfert EA, Grainger JR, Bouladoux N, Konkel JE, Oldenhove $\mathrm{G}$, Ribeiro $\mathrm{CH}$, et al. GATA3 controls Foxp3(+) regulatory $\mathrm{T}$ cell fate during inflammation in mice. J Clin Invest. (2011) 121:4503-15. doi: 10.1172/JCI57456

24. Hori S, Nomura T, Sakaguchi S. Control of regulatory T cell development by the transcription factor Foxp3. Science. (2003) 299:1057-61. doi: 10.1126/science. 1079490

25. Pandiyan P, Zheng L, Ishihara S, Reed J, Lenardo MJ. CD4+CD25+Foxp3+ regulatory $\mathrm{T}$ cells induce cytokine deprivation-mediated apoptosis of effector CD4+ T cells. Nat Immunol. (2007) 8:1353-62. doi: 10.1038/ ni1536

26. Sun Z, Ren Z, Yang K, Liu Z, Cao S, Deng S, et al. A next-generation tumor-targeting IL-2 preferentially promotes tumor-infiltrating CD8(+) Tcell response and effective tumor control. Nat Commun. (2019) 10:3874. doi: 10.1038/s41467-019-11782-w

27. Mizui M. Natural and modified IL-2 for the treatment of cancer and autoimmune diseases. Clin Immunol. (2019) 206:63-70. doi: 10.1016/j.clim.2018.11.002

28. Ye C, Brand D, Zheng SG. Targeting IL-2: an unexpected effect in treating immunological diseases. Signal Transduct Target Ther. (2018) 3:2. doi: 10.1038/s41392-017-0002-5

29. Schneider H, Downey J, Smith A, Zinselmeyer BH, Rush C, Brewer JM, et al. Reversal of the TCR stop signal by CTLA-4. Science. (2006) 313:1972-5. doi: $10.1126 /$ science. 1131078 
30. Chambers CA, Sullivan TJ, Allison JP. Lymphoproliferation in CTLA-4deficient mice is mediated by costimulation-dependent activation of CD4+ T cells. Immunity. (1997) 7:885-95. doi: 10.1016/S1074-7613(00)80406-9

31. Bulliard Y, Jolicoeur R, Windman M, Rue SM, Ettenberg S, Knee DA, et al. Activating Fc gamma receptors contribute to the antitumor activities of immunoregulatory receptor-targeting antibodies. J Exp Med. (2013) 210:1685-93. doi: 10.1084/jem.20130573

32. Selby MJ, Engelhardt JJ, Quigley M, Henning KA, Chen T, Srinivasan M, et al. Anti-CTLA-4 antibodies of IgG2a isotype enhance antitumor activity through reduction of intratumoral regulatory T cells. Cancer Immunol Res. (2013) 1:32-42. doi: 10.1158/2326-6066.CIR-13-0013

33. Simpson TR, Li F, Montalvo-Ortiz W, Sepulveda MA, Bergerhoff K, Arce $\mathrm{F}$, et al. Fc-dependent depletion of tumor-infiltrating regulatory $\mathrm{T}$ cells codefines the efficacy of anti-CTLA-4 therapy against melanoma. J Exp Med. (2013) 210:1695-710. doi: 10.1084/jem.20130579

34. Sharma A, Subudhi SK, Blando J, Scutti J, Vence L, Wargo J, et al. Anti-CTLA-4 immunotherapy does not deplete FOXP3(+) regulatory $\mathrm{T}$ cells (Tregs) in human cancers. Clin Cancer Res. (2019) 25:1233-8. doi: 10.1158/1078-0432.CCR-18-0762

35. Ha D, Tanaka A, Kibayashi T, Tanemura A, Sugiyama D, Wing JB, et al. Differential control of human Treg and effector $\mathrm{T}$ cells in tumor immunity by Fc-engineered anti-CTLA-4 antibody. Proc Natl Acad Sci USA. (2019) 116:609-18. doi: 10.1073/pnas.1812186116

36. Hodi FS, Butler M, Oble DA, Seiden MV, Haluska FG, Kruse A, et al. Immunologic and clinical effects of antibody blockade of cytotoxic $\mathrm{T}$ lymphocyte-associated antigen 4 in previously vaccinated cancer patients. Proc Natl Acad Sci USA. (2008) 105:3005-10. doi: 10.1073/pnas.0712237105

37. Shimizu J, Yamazaki S, Sakaguchi S. Induction of tumor immunity by removing CD25+CD4+ T cells: a common basis between tumor immunity and autoimmunity. J Immunol. (1999) 163:5211-8.

38. Onizuka S, Tawara I, Shimizu J, Sakaguchi S, Fujita T, Nakayama E. Tumor rejection by in vivo administration of anti-CD25 (interleukin-2 receptor alpha) monoclonal antibody. Cancer Res. (1999) 59:3128-33.

39. Curiel TJ, Coukos G, Zou L, Alvarez X, Cheng P, Mottram P, et al. Specific recruitment of regulatory $\mathrm{T}$ cells in ovarian carcinoma fosters immune privilege and predicts reduced survival. Nat Med. (2004) 10:942-9. doi: $10.1038 / \mathrm{nm} 1093$

40. Facciabene A, Peng X, Hagemann IS, Balint K, Barchetti A, Wang LP, et al. Tumour hypoxia promotes tolerance and angiogenesis via CCL28 and T(reg) cells. Nature. (2011) 475:226-30. doi: 10.1038/nature10169

41. Nishikawa H, Kato T, Tawara I, Saito K, Ikeda H, Kuribayashi K, et al. Definition of target antigens for naturally occurring CD4(+) CD25(+) regulatory T cells. J Exp Med. (2005) 201:681-6. doi: 10.1084/jem.20041959

42. Sainz-Perez A, Lim A, Lemercier B, Leclerc C. The T-cell receptor repertoire of tumor-infiltrating regulatory $\mathrm{T}$ lymphocytes is skewed toward public sequences. Cancer Res. (2012) 72:3557-69. doi: 10.1158/0008-5472.CAN-12-0277

43. Wang YA, Li XL, Mo YZ, Fan CM, Tang L, Xiong F, et al. Effects of tumor metabolic microenvironment on regulatory T cells. Mol Cancer. (2018) 17:168. doi: 10.1186/s12943-018-0913-y

44. Gerriets VA, Kishton RJ, Johnson MO, Cohen S, Siska PJ, Nichols AG, et al. Foxp3 and Toll-like receptor signaling balance Treg cell anabolic metabolism for suppression. Nat Immunol. (2016) 17:1459-66. doi: 10.1038/ni.3577

45. Stockis J, Roychoudhuri R, Halim TYF. Regulation of regulatory T cells in cancer. Immunology. (2019) 157:219-31. doi: 10.1111/imm.13064

46. Akimova T, Zhang T, Negorev D, Singhal S, Stadanlick J, Rao A, et al. Human lung tumor FOXP3+ Tregs upregulate four "Treg-locking" transcription factors. JCI Insight. (2017) 2:e94075. doi: 10.1172/jci.insight.94075

47. Jie HB, Gildener-Leapman N, Li J, Srivastava RM, Gibson SP, Whiteside $\mathrm{TL}$, et al. Intratumoral regulatory $\mathrm{T}$ cells upregulate immunosuppressive molecules in head and neck cancer patients. Br J Cancer. (2013) 109:2629-35. doi: 10.1038/bjc.2013.645

48. Strauss L, Bergmann C, Szczepanski MJ, Lang S, Kirkwood JM, Whiteside TL. Expression of ICOS on human melanoma-infiltrating CD4+CD25highFoxp3 $+\mathrm{T}$ regulatory cells: implications and impact on tumor-mediated immune suppression. J Immunol. (2008) 180:2967-80. doi: 10.4049/jimmunol.180.5.2967
49. Kamada T, Togashi Y, Tay C, Ha D, Sasaki A, Nakamura Y, et al. $\mathrm{PD}-1(+)$ regulatory $\mathrm{T}$ cells amplified by $\mathrm{PD}-1$ blockade promote hyperprogression of cancer. Proc Natl Acad Sci USA. (2019) 116:9999-10008. doi: $10.1073 /$ pnas. 1822001116

50. Kooshkaki O, Derakhshani A, Hosseinkhani N, Torabi M, Safaei S, Brunetti $\mathrm{O}$, et al. Combination of ipilimumab and nivolumab in cancers: from clinical practice to ongoing clinical trials. Int J Mol Sci. (2020) 21:4427. doi: 10.3390/ijms21124427

51. Warner AB, Postow MA. Combination controversies: checkpoint inhibition alone or in combination for the treatment of melanoma? Oncology. (2018) 32:228-34.

52. Tanaka A, Sakaguchi S. Regulatory T cells in cancer immunotherapy. Cell Res. (2017) 27:109-18. doi: 10.1038/cr.2016.151

53. Arce Vargas F, Furness AJS, Solomon I, Joshi K, Mekkaoui L, Lesko MH, et al. Fc-Optimized anti-CD25 depletes tumor-infiltrating regulatory $\mathrm{T}$ cells and synergizes with $\mathrm{PD}-1$ blockade to eradicate established tumors. Immunity. (2017) 46:577-86. doi: 10.1016/j.immuni.2017. 03.013

54. Sato K, Sato N, Xu B, Nakamura Y, Nagaya T, Choyke PL, et al. Spatially selective depletion of tumor-associated regulatory $\mathrm{T}$ cells with near-infrared photoimmunotherapy. Sci Transl Med. (2016) 8:352ra110. doi: 10.1126/scitranslmed.aaf6843

55. Solomon I, Amann M, Goubier A, Arce Vargas F, Zervas D, Qing C, et al. CD25-Treg-depleting antibodies preserving IL-2 signaling on effector T cells enhance effector activation and antitumor immunity. Nat Cancer. (2020) 1:1153-66. doi: 10.1038/s43018-020-00133-0

56. De Simone M, Arrigoni A, Rossetti G, Gruarin P, Ranzani V, Politano C, et al. Transcriptional landscape of human tissue lymphocytes unveils uniqueness of tumor-infiltrating $\mathrm{T}$ regulatory cells. Immunity. (2016) 45:1135-47. doi: 10.1016/j.immuni.2016.10.021

57. Valzasina B, Guiducci C, Dislich H, Killeen N, Weinberg AD, Colombo MP. Triggering of OX40 (CD134) on CD4(+)CD25+ T cells blocks their inhibitory activity: a novel regulatory role for OX40 and its comparison with GITR. Blood. (2005) 105:2845-51. doi: 10.1182/blood-2004-07-2959

58. Curti BD, Kovacsovics-Bankowski M, Morris N, Walker E, Chisholm $\mathrm{L}$, Floyd $\mathrm{K}$, et al. OX40 is a potent immune-stimulating target in late-stage cancer patients. Cancer Res. (2013) 73:7189-98. doi: 10.1158/0008-5472.CAN-12-4174

59. Glisson BS, Leidner RS, Ferris RL, Powderly J, Rizvi NA, Keam B, et al. Safety and clinical activity of MEDI0562, a humanized OX40 agonist monoclonal antibody, in adult patients with advanced solid tumors. Clin Cancer Res. (2020) 26:5358-67. doi: 10.1158/1078-0432.CCR-19-3070

60. Heinhuis KM, Carlino M, Joerger M, Di Nicola M, Meniawy T, Rottey S, et al. Safety, tolerability, and potential clinical activity of a glucocorticoidinduced TNF receptor-related protein agonist alone or in combination with nivolumab for patients with advanced solid tumors: a phase $1 / 2 \mathrm{a}$ doseescalation and cohort-expansion clinical trial. JAMA Oncol. (2019) 6:1-8. doi: 10.1001/jamaoncol.2019.3848

61. Sugiyama D, Nishikawa H, Maeda Y, Nishioka M, Tanemura A, Katayama I, et al. Anti-CCR4 mAb selectively depletes effector-type FoxP3+CD4+ regulatory $\mathrm{T}$ cells, evoking antitumor immune responses in humans. Proc Natl Acad Sci USA. (2013) 110:17945-50. doi: 10.1073/pnas.13167 96110

62. Togashi Y, Shitara K, Nishikawa H. Regulatory $T$ cells in cancer immunosuppression - implications for anticancer therapy. Nat Rev Clin Oncol. (2019) 16:356-71. doi: 10.1038/s41571-019-0175-7

63. Tan MC, Goedegebuure PS, Belt BA, Flaherty B, Sankpal N, Gillanders WE, et al. Disruption of CCR5-dependent homing of regulatory $\mathrm{T}$ cells inhibits tumor growth in a murine model of pancreatic cancer. J Immunol. (2009) 182:1746-55. doi: 10.4049/jimmunol.182.3.1746

64. Arvey A, van der Veeken J, Samstein RM, Feng Y, Stamatoyannopoulos JA, Rudensky AY. Inflammation-induced repression of chromatin bound by the transcription factor Foxp3 in regulatory T cells. Nat Immunol. (2014) 15:580-7. doi: 10.1038/ni.2868

65. Tiffen JC, Gallagher SJ, Tseng HY, Filipp FV, Fazekas de St. Groth B, Hersey P. EZH2 as a mediator of treatment resistance in melanoma. Pigment Cell Melanoma Res. (2016) 29:500-7. doi: 10.1111/pcmr.12481 
66. Wang D, Quiros J, Mahuron K, Pai CC, Ranzani V, Young A, et al. Targeting EZH2 reprograms intratumoral regulatory $\mathrm{T}$ cells to enhance cancer immunity. Cell Rep. (2018) 23:3262-74. doi: 10.1016/j.celrep.2018.05.050

67. Yates K, Bi K, Haining WN, Cantor H, Kim HJ. Comparative transcriptome analysis reveals distinct genetic modules associated with Helios expression in intratumoral regulatory T cells. Proc Natl Acad Sci USA. (2018) 115:2162-7. doi: 10.1073/pnas.1720447115

68. Wang H, Franco F, Tsui YC, Xie X, Trefny MP, Zappasodi R, et al. CD36-mediated metabolic adaptation supports regulatory $\mathrm{T}$ cell survival and function in tumors. Nat Immunol. (2020) 21:298-308. doi: 10.1038/s41590-019-0589-5

69. Donkor MK, Sarkar A, Savage PA, Franklin RA, Johnson LK, Jungbluth $\mathrm{AA}$, et al. $\mathrm{T}$ cell surveillance of oncogene-induced prostate cancer is impeded by T cell-derived TGF-betal cytokine. Immunity. (2011) 35:123-34. doi: 10.1016/j.immuni.2011.04.019

70. Sarkar A, Donkor MK, Li MO. T cell- but not tumor cell-produced TGF-beta1 promotes the development of spontaneous mammary cancer. Oncotarget. (2011) 2:1339-51. doi: 10.18632/oncotarget.403

71. Donkor MK, Sarkar A, Li MO. Tgf-betal produced by activated CD4(+) T cells antagonizes T cell surveillance of tumor development. Oncoimmunology. (2012) 1:162-71. doi: 10.4161/onci.1.2.18481

72. Li S, Liu M, Do MH, Chou C, Stamatiades EG, Nixon BG, et al. Cancer immunotherapy via targeted TGF-beta signalling blockade in TH cells. Nature. (2020) 587:1-5. doi: 10.1038/s41586-020-2850-3
73. Hanson A, Elpek K, Duong E, Shallberg L, Fan M, Johnson C, et al. ICOS agonism by JTX-2011 (vopratelimab) requires initial T cell priming and $\mathrm{Fc}$ cross-linking for optimal $\mathrm{T}$ cell activation and antitumor immunity in preclinical models. PLoS ONE. (2020) 15:e0239595. doi: 10.1371/journal.pone.0239595

74. Solinas C, Gu-Trantien C, Willard-Gallo K. The rationale behind targeting the ICOS-ICOS ligand costimulatory pathway in cancer immunotherapy. ESMO Open. (2020) 5:e000544. doi: 10.1136/esmoopen-2019-000544

75. Yu T, Wang Y, Hu Q, Wu W, Wu Y, Wei W, et al. The EZH2 inhibitor GSK343 suppresses cancer stem-like phenotypes and reverses mesenchymal transition in glioma cells. Oncotarget. (2017) 8:98348-59. doi: 10.18632/oncotarget.21311

Conflict of Interest: The authors declare that the research was conducted in the absence of any commercial or financial relationships that could be construed as a potential conflict of interest.

Copyright (c) 2021 González-Navajas, Fan, Yang, Yang, Lozano-Ruiz, Shen and Lee. This is an open-access article distributed under the terms of the Creative Commons Attribution License (CC BY). The use, distribution or reproduction in other forums is permitted, provided the original author(s) and the copyright owner(s) are credited and that the original publication in this journal is cited, in accordance with accepted academic practice. No use, distribution or reproduction is permitted which does not comply with these terms. 